\title{
Los mecanismos de democracia directa en Cuba: diseño normativo y práctica
}

(Teodoro) Yan Guzman Hernández*

Perfiles Latinoamericanos, 25(50)

2017 | pp. 103-127

DOI: $10.18504 / \mathrm{pl} 2550-006-2017$

\begin{abstract}
Resumen
La Constitución cubana de 1940 reguló varios mecanismos de democracia directa (MDD) que no se pusieron en práctica; mientras que la vigente de 1976, aunque se comprometió con la participación directa y la soberanía popular, fue poco ambiciosa en su regulación. Después de la Revolución, la participación directa ha tenido manifestaciones denominadas erróneamente MDD. Este artículo aborda los mecanismos de democracia directa en Cuba, y para ello desarrolla un análisis crítico de su regulación, con los criterios que la teoría política y el derecho constitucional ofrecen para su configuración, y teniendo en cuenta las particularidades y resultados de su puesta en práctica en el contexto cubano. La principal conclusión es que en Cuba se regulan formas de participación que involucran directamente a la ciudadanía, pero que requieren cambios en su diseńo, a fin de que se conviertan en reales mecanismos de democracia directa que coadyuven al empoderamiento político de los ciudadanos.
\end{abstract}

\begin{abstract}
In Cuba the 1940 Constitution regulated different mechanisms of direct democracy (MDD) that were not implemented; while the 1976 Constitution in force, although committed from the norm with the direct participation and popular sovereignty, was unambitious in regulating these mechanisms. After the Revolution, direct participation has had different expressions that have been nominated wrongly as some of the MDD, that political theory today recognizes on the basis of certain assumptions. This article examines the MDD in Cuba from 1940 until the present. For this purpose it makes a critical analysis of its regulation, based on the criteria that political theory and constitutional law have offered for the configuration of these mechanisms, and taking into account the particularities and results of the implementation in the Cuban context. The main conclusion of this work is that Cuba regulates forms of participation that directly involve the citizenry, but require changes in its design, so that they become real mechanisms of direct democracy that contribute to the political empowerment of citizens.
\end{abstract}

Palabras clave: participación, referendo, revocatoria, iniciativa, constitución, democracia directa. Keywords: Participation, referendum, recall, initiative, constitution, direct democracy.

* Profesor Titular de Derecho Constitucional y Teoría del Derecho, Universidad de La Habana | yan@lex.uh.cu 


\section{Precisiones sobre los mecanismos de democracia directa $\mathrm{y}$ advertencias sobre este tema en Cuba}

a práctica de los mecanismos de democracia directa (MDD) en Cuba ha sido irrelevante en tres cuartos de siglo, a pesar, primero, de su amplio reconocimiento en la Constitución de 1940, uno de los textos más avanzados de América Latina, incluso en el tema en cuestión, ${ }^{1}$ y segundo, de que la vigente Constitución — que data de 1976 con reformas — ha regulado algunos de esos mecanismos sobre la base discursiva de la participación popular, pero en los límites de la democracia socialista ${ }^{2}$ y la soberanía popular.

Esos textos constitucionales han respondido a una diferente concepción de la estructuración y ejercicio del poder, y de la relación entre el ciudadano y el Estado. La Constitución de 1940, a pesar de sustentarse en un modelo de democracia representativa, apostó por la democracia local con influencia norteamericana. Para ello se apoyó en la descentralización y autonomía municipal (herencia de la Ley Orgánica del Régimen Municipal de 1908) y, consecuentemente, en un grupo de instituciones y dinámicas participativas que la reforzaban, pero que lamentablemente quedaron en "letra muerta". En cambio, la Constitución socialista de 1976 concibió al Poder Popular como una estructura organizativa del Estado, y a la soberanía popular y a la democracia socialista como dos principios rectores, pero es un modelo signado por un marcado estatismo y una escasísima descentralización, que en casi cuatro décadas solo ha tenido modestos progresos.

El boom discursivo y analítico de los MDD es posterior a dichas Constituciones, pero desde mucho antes la doctrina constitucional había reconocido la existencia y regulación de los medios de la participación directa del pueblo, comúnmente bajo la denominación de instituciones de democracia semidirecta o directa, como todavía suele llamárseles hoy (Zovatto, 2007), solo que el diseño institucional de estos mecanismos, el contexto político en que se ha fomentado su regulación y concreción, los efectos políticos, así como su sistematización y tipología, han sido un ejercicio propio de la teoría política.

1 La Constitución uruguaya de 1934 es vanguardia en América Latina respecto al reconocimiento de los MDD, aunque la de 1919 de ese país ya había regulado varios de ellos para el nivel local (Zovatto, 2007: p. 10).

2 La "omnipotencia de la representación" quedó reconocida en casi todas las Constituciones socialistas, situación jurídico-política que en algunas quedó enfatizada normativamente, como por ejemplo la soviética de 1936. Las excepciones fueron la cubana de 1976 y las yugoslavas de 1963 y 1974, que contrajeron mayores compromisos normativos con la democracia directa. Sin embargo, una característica común de la regulación de las instituciones de democracia directa en las constituciones socialistas, fue la ausencia de garantías en la mayoría de los casos, y su carácter no vinculante, lo que limitó su utilidad (Bihari, 1979: p. 244). 
Algunas manifestaciones de la participación política en Cuba han sido abordadas bajo el manto de la democracia directa, pero sin diseccionar sus diferentes expresiones, de forma tal que permitan determinar los aciertos y desaciertos de su configuración. Esto ha provocado cierto espejismo valorativo sobre las formas y medios que han canalizado la participación directa.

Con el triunfo de la Revolución, la participación directa se identificó con manifestaciones que implicaron al pueblo subjetivado en masa reivindicatoria de los grandes sectores hasta ese momento excluidos, pero en la gran mayoría de aquellas no medió el uso del voto. Ha englobado en cambio variadas formas de participación popular, que han sido funcionales para demostrar de manera incontrastable el apoyo popular a decisiones políticas trascendentes, como a inicios de la Revolución con la Primera y Segunda Declaración de La Habana en 1961 y 1962, respectivamente; o para sostener que el pueblo ha tenido la dirección y control de la sociedad (Alarcón, 2002: p. 51), lo que ha llevado a considerar que la colaboración de los sindicatos y organizaciones de masas en las tareas estatales (Garcini, 1976: p. 108) y los Parlamentos obreros de 1994 (Alarcón, 2002: p. 14), serían expresiones de la democracia directa en su sentido más amplio.

Otras prácticas que también se han defendido como ejercicio de democracia directa en Cuba, han estado relacionadas con la participación ciudadana en el proceso legislativo, lo cual proviene de la consulta popular que promueve la Asamblea Nacional (Garcini, 1976: p. 110) y del debate que involucra a la ciudadanía en la discusión de los proyectos de ley. Antes de su regulación, esta dinámica tuvo sus primeras expresiones luego de 1973, durante la elaboración de un conjunto de leyes en el marco de la institucionalización revolucionaria, así como en la concepción de la vigente Carta Magna (Marill, 1980: p. 129); posteriormente, se usó para legitimar proyectos de ley que la desarrollaron (Nogueras, 2006: p. 495), y en la actualidad ha recobrado fuerza, lo que se evidencia en las consultas y discusiones populares de los Lineamientos de la Política Social y Económica del Partido y la Revolución (2011), y de la reforma al Código de Trabajo (2013).

La concepción amplia de la democracia directa y la autosuficiencia de sus variadas expresiones, en pos de la legitimidad del sistema, ha desviado la atención que en Cuba deben merecer los MDD, regulados desde 1976, y que hoy se identifican a través de instituciones participativas de orden constitucional o infraconstitucional.

De ahí que este trabajo examine los principales aspectos de la regulación de los MDD en Cuba desde 1940 hasta la actualidad, y delimite algunas manifestaciones de la participación directa que no se deben identificar con esos mecanismos, no obstante que así se les haya considerado hasta ahora. Al mismo tiempo se realizarán propuestas que contribuyan a reforzar los que hoy se encuentran regulados. El perfil constitucional de este trabajo se justifica en parte porque 
la mayoría de los MDD en Cuba han quedado sin aplicación, por lo que obliga a encuadrar el análisis en su diseño normativo; pese a esto no se renunciará al examen de los contextos político-jurídicos en los que se han desarrollado las pocas prácticas de estos mecanismos, en el periodo seleccionado. ${ }^{3}$

Dentro de los mecanismos de democracia directa se inscribe la iniciativa ciudadana que engloba a la legislativa popular y la de agenda (International IDEA Handbook, 2008: p. 11). La primera consiste en que los ciudadanos promueven un proyecto de ley (en sentido lato) o de reforma a la Constitución, con el respaldo de una cantidad de firmas prevista legalmente, y el órgano receptor (casi siempre el legislativo) lo somete a consulta popular o lo adopta formalmente; mientras que en la segunda, la promoción respaldada con firmas solo obliga al órgano legislativo receptor a que lo debata, enmiende y someta a su aprobación, pero no conlleva una votación popular, por lo que no tiene efecto vinculante (IDEA, 2008: pp. 11, 61, 198).

Dentro de los MDD también se encuentran el plebiscito y el referendo, este último con su propia tipología ${ }^{4}$ y al que se puede llegar mediante una iniciativa ciudadana. En ambos casos se promueve una consulta popular sobre aspectos concretos del orden político-jurídico. Desde una perspectiva constitucional, en un primer momento se enfatizó en la esencia jurídica o política de la materia sometida a consulta para distinguir a uno y a otro (García, 1961: p. 184). Se ha argüido que con el referendo se somete al electorado una cuestión de naturaleza jurídica, o sea, susceptible de convertirse en disposición jurídica, mientras que el plebiscito sería un acto de naturaleza gubernamental o constitucional. Sin embargo, en el perfil descriptivo de cada uno falta una definición unívoca que los diferencie. El término plebiscito se ha empleado para indicar una votación popular en eventos políticos excepcionales no previstos constitucionalmente (Bobbio et al., 1983: p. 815). Pero quienes abordan los MDD (desde la teoría política, principalmente) los distinguen con base en quienes promueven la consulta;

3 Cabe reconocer que un análisis desde la teoría y sociología políticas contribuiría a entender muchas de las limitaciones en la regulación de los MDD en Cuba, en el sentido de su funcionalidad sistémica, misma que ha apuntado a una autolegitimación del poder estatal. La concepción política de "Estado de todo el pueblo" que trascendió a la institucionalización normativa y a la praxis política, ha sido un factor clave para que los MDD hayan quedado regulados en Cuba de forma tal que la materialización de intereses ciudadanos contrapuestos a los estatales sea poco probable. Este elemento responde a dinámicas políticas ya identificadas, al menos como lo ha entendido la teoría política liberal, con regímenes autoritarios, no solo por el control de la participación en lo que se refiere a momentos de expresión, cauce y efectos, sino porque se suma a cuestiones medulares como, por ejemplo, la falta de competencia política producto del monopartidismo de partido único existente.

4 Svenson (2011) en "Forms and terminology of direct democracy" trae a colación las clasificaciones del referendo hechas por Markku Suksy, Auer, Buttler y Ranney. Desde una perspectiva normativa, la Constitución de Weimar (1919) estableció seis tipos de referendo, y cuatro la Bolivariana de Venezuela (1999). 
así, cuando los promotores son el ejecutivo o el legislativo, les dan naturaleza plebiscitaria (Kaufmann \& Waters, 2004. Citado por Altman, 2011: p. 10).

La inclusión de la revocatoria de mandato dentro de estas instituciones o mecanismos no ha sido pacíficamente aceptada, por ser una institución que tiene como objetivo personas y no temas (Kaufmann, Buchi \& Braun, 2008. Citado por Altman, 2011: p. 16). Al margen de lo anterior, la revocatoria o recall ha tenido su propia tipología, dependiendo de si la ciudadanía interviene solo en una de sus dos fases principales (solicitud de revocación o consulta donde se decide esta) o en ambas. Al primer supuesto se le ha denominado revocatoria mixta (mixed recall), y al segundo, revocatoria completa (full recall) (IDEA, 2008: p. 130).

Algunas formas de participación directa han quedado excluidas de los MDD por no canalizarse y garantizarse mediante el sufragio universal y secreto, a la vez que este los configura (Altman, 2011: p. 7). De igual manera, se ha referido que se los conciba de forma restringida encuadrando solo a los que permitan que la ciudadanía decida directamente en las urnas, al margen de quien solicite la consulta (Welp, 2010: p. 29; Altman, 2010: p. 12); en esta lógica Altman excluye la iniciativa legislativa popular (que no conlleva votación), pues considera que es una herramienta de control de agenda y no de decisión política (Altman, 2011: p. 17). A pesar de esto, algunos mecanismos marginados por esta concepción restringida han tenido efectos políticos constatables, lo que ejemplifican ciertos referendos consultivos en América Latina como el colombiano "La séptima papeleta" que promovieron los estudiantes en 1990 (Welp, 210: p. 29), el cual condujo a la instauración de una Asamblea Constituyente que reformó la Constitución de ese país de 1886 y dio paso a la de 1991.

De cualquier manera, una definición amplia de los MDD - la que se asume en este artículo- se configuraría con base en la participación ciudadana, con efecto decisorio o influyente, verificado en las urnas o con la recolecta de un número determinado de firmas - como procedimiento establecido legalmente-, y cuyo objetivo sería lograr una votación popular o una decisión de los órganos representativos. Se excluye la elección de cargos públicos, lo que ha sido común en las diferentes definiciones de los MDD (Rial, 2000: p. 1; Zovatto, 2007: p. 1; Thibaut, 2003: p. 67; Altman, 2011: p. 7).

La elección es la causa técnica de la representación política, y los MDD actúan como su complemento; sobre esta base, se les podría definir como formas de participación ciudadana que tienen el objetivo de modificar o influir en el ejercicio de la representación política, en lo concerniente a su estructura subjetiva (los representantes) o a su dinámica objetiva (la decisión política).

Desde esta perspectiva, hasta la fecha en Cuba, una consulta popular vinculante (considerada referendo para unos y plebiscito para otros) y una decreciente revocatoria de mandato para el nivel municipal, han sido sus únicas e 
incontrovertibles manifestaciones consumadas. A ello súmese, si se pretende ampliar el análisis, un intento fallido de iniciativa legislativa popular, o de reforma constitucional, y una recolecta de firmas de adhesión, declarada erróneamente como plebiscito por la propia Asamblea Nacional y oficializada con esa denominación (véase la Nota de la Asamblea Nacional en la Constitución de la República de Cuba, G. O. nº 3, 31 de enero de 2003).

Las referencias y análisis de la regulación y práctica de la democracia directa en Cuba han sido omitidas en trabajos sobre el tema, ya sea al relacionar los países que cuentan con MDD en América Latina para el nivel nacional (Rial, 2000: pp. 3-6; Zovatto, 2007: p. 9; Hevia, 2010: p. 175), ya al pasar revista por el reconocimiento y/o puesta en práctica de estos en el mismo contexto geográfico (Thibaut, 1998: p. 70; La Madrid, 2002: pp. 435-436; Lissidini, 2008: pp. 13-63; Welp, 2010: pp. 31-32). En otros casos, la información al respecto no ha sido exacta, por ejemplo, el International Direct Democracy Handbook sostuvo que no se definió el procedimiento para hacer efectiva la revocatoria de mandato (IDEA, 2008: p. 110), además, si bien refirió su reconocimiento y regulación en Cuba junto al referendo (2008: pp. 179, 205), obvió la iniciativa que en Cuba pueden tener diez mil ciudadanos para presentar un proyecto de ley a la Asamblea Nacional cuando relacionó los países que regulaban la iniciativa legislativa (2008: p. 63) o de agenda (2008: p. 86), si bien es válido destacar, aunque sea como excepción, que se ha reconocido la existencia y puesta en práctica de algunos de estos mecanismos en Cuba (Altman, 2005: p. 218; 2010: p. 20).

Omisiones e inexactitudes pueden estar dadas por una toma de postura frente al modelo político cubano debida a valoraciones sobre su vis democrática, en especial en cuanto a pluripartidismo, separación de poderes, elecciones competitivas o libertades individuales oponibles al Estado (prensa, asociación y expresión); también pudiera ser porque lo que se ha entendido como democracia directa en Cuba ha englobado expresiones predominantes que no han interesado a los que han circunscrito el tema a los MDD en los que el voto es sine qua non. Otra razón pudiera ser la notable escasez de trabajos escritos desde la Isla que ofrezcan información y estadística sobre la regulación y uso de estos en Cuba, ${ }^{5}$ además de las dificultades para acceder a información relacionada con su puesta en práctica, a través de fuentes públicas nacionales. ${ }^{6}$

5 En Guanche (2011: pp. 58-63, 106-111), se examinan los derechos políticos de participación entre los que se incluyen algunos de los MDD. Guanche resalta las limitaciones de estos últimos luego de la reforma constitucional de 1992, y a partir del avance del nuevo constitucionalismo latinoamericano. La dirección en este artículo es contraria, pues se considera que la regulación de los MDD en Cuba tienen un precedente relevante en la Constitución de 1940.

6 La Oficina Nacional de Estadística (http://www.one.cu) solo ofrece información sobre las elecciones parciales y generales que se han celebrado en Cuba desde 1980 hasta la actualidad, mientras que la Co- 
Ahora bien, un aspecto importante en el examen de los MDD sería su perspectiva funcional, o sea, ¿cómo activarlos?, ¿qué utilidad tendrían y cuáles serían las consecuencias de su uso? Interesaría si son promovidos "desde abajo" por la ciudadanía, "desde arriba" por las instancias del poder público legitimadas (casi siempre legislativo y ejecutivo), o porque operan directamente por mandato de Constitución o ley ante determinadas situaciones políticas previstas. Interesarían también sus fines entendidos en la capacidad que tengan para subvertir o reafirmar el statu quo, ${ }^{7}$ así como su eventual carácter vinculante. Respecto a esto último, las instancias representativas en principio ${ }^{8}$ no tendrían oportunidad de desconocer el resultado de la consulta, cuestión que se debe poner en evidencia en los referendos no consultivos, en la revocatoria de mandato o en las iniciativas legislativas directas (siguiendo la clasificación de Hevia, 2010: p. 161).

La ciencia política ha prestado singular atención a lo que podría denominarse perspectiva funcional de los MDD, lo que ha servido para su caracterización y cualificación. Jürgen Fijalkowski ha hablado de mecanismos que adoptan "formas fuertes" o "débiles" (citado en Thibaut, 1998: p. 80), y existe una variada tipologías desarrollada por Vincenzo Uleri, el International IDEA, el Initiative and Referendum Institute Europe (IRI Europe) y Altman (véase un análisis comparativo de estas en Svenson, 2011: pp. 20-26).

De cualquier manera, la puesta en práctica de los MDD no dependerá únicamente de su diseño, porque también influyen otros aspectos del sistema político y de la sociedad en sentido general, tales como la cultura participativa (Valdés, 2009: p. 165), la trascendencia de las decisiones políticas que se sometan a la ciudadanía, el grado de simetría con el que se construya la relación

misión Electoral Nacional, no cuenta con una web con datos y estadísticas relacionados con la práctica de la participación directa.

7 La propuesta "bipolar" de Altman respecto a los fines de los MDD (subvertir o mantener el statu quo) para determinadas situaciones, puede terminar marginando las complejidades del sistema político, incluso de las relaciones políticas (distensiones o desacuerdos) entre legislativo y ejecutivo, cuestión que este autor advierte cuando refiere los criterios de Vatter (2009) (Altman, 2011: p. 20). Esto podría reflejarse en el comportamiento de la ciudadanía, a través de la manifestación y la construcción de apoyos y lealtades hacia los actores políticos implicados en el conflicto. Por otra parte, las iniciativas de consultas del ejecutivo o del legislativo pueden estar encaminadas a recabar apoyo ciudadano para una decisión que el otro órgano no comparte. Esta tesis se manifiesta en mecanismos que podrían verse con fines solucionadores de esos conflictos, como por ejemplo, el histórico referendo de arbitraje del artículo 74 de la Constitución de Weimar (1919), y más actual, el caso chileno para resolver los conflictos entre ejecutivo y legislativo en el marco de una reforma constitucional (arts. 128 y 129 de la Constitución).

8 Hay casos en los que las estructuras estatales han desestimado el resultado de la consulta popular realizada a pesar de su carácter vinculante. Un ejemplo fue el plebiscito convocado por el presidente de Zimbawe, Robert Mugabe, en el cual la mayoría de los zimbaweses (54.7\%) votaron no a la propuesta constitucional de Mugabe. El resultado no fue aceptado aludiéndose que la participación había sido muy baja (26\% aproximadamente), algo que no estaba previsto legalmente (Altman, 2011: p. 107).

(T.) Y. Guzman Hernández | Los mecanismos de democracia directa en Cuba: diseño normativo y práctica Perfiles Latinoamericanos, 25(50) | FLACSO México | pp. 103-127 | Dor: 10.18504/pl2550-006-2017 
democrática entre la ciudadanía y las estructuras decisorias del Estado, entre otras cuestiones; sin embargo, de ninguna manera puede renunciarse a su democratización, la cual parte desde su variado reconocimiento en la Constitución y las normas reglamentarias, de manera tal que se logre un diseño normativo de los presupuestos configurativos del mecanismo que facilite la participación. No por gusto, países como Suiza, Uruguay y Ecuador donde más se han puesto en uso los MDD (Altman, 2011: pp. 73,117) presentan diseños factibles que propenden a su materialización.

\section{La regulación constitucional de los MDD antes de la Constitución de 1976}

La Constitución de 1940 reconoció diversos MDD, tales como las iniciativas ciudadanas, el referendo y la revocatoria de mandato. El diseño de la mayoría no se reglamentó por omisión del legislador, o porque faltaron muchas leyes de desarrollo de la Constitución, o no se tuvieron en cuenta en la codificación electoral.

Tres propósitos fundamentales tuvo la regulación de los MDD en la Constitución de 1940: garantizar la autonomía del municipio, proteger determinados contenidos que habían causado inestabilidad política, y defender la Constitución de componendas políticas o fraudes contra ella que marginaran al pueblo, en su condición de poder constituyente. Los tres aspectos tenían precedentes negativos que se trataba de evitar. El primero era que la adelantada Ley Orgánica del Régimen Municipal de 1908 había quedado sin garantías constitucionales que reforzaran su aplicación, lo que provocó que los municipios se redujeran a meras oficinas recaudadoras y espacios de la baja política (Capablanca, 1940: p. 184); el segundo tenía como antecedente la espuria reforma constitucional de 1928 que había permitido la prórroga en el poder y la reelección del dictador Gerardo Machado, y el tercero, relacionado con lo anterior, era que la reforma a la Constitución había sido hecha por una Convención constituyente sin legitimidad para realizar una reforma integral, y que tampoco estaba facultada para declararse soberana y someter a los poderes constituidos (Álvarez-Tabío, 1953: p. 10).

Entre los elementos que llaman la atención de los MDD en la Constitución de 1940 se encuentran el amplio reconocimiento de las iniciativas ciudadanas, la previsión de varios supuestos en los que el referendo era de carácter obligatorio, y la regulación de la revocatoria de mandato de tipo mixta circunscrita al municipio. De hecho fue en ese ámbito del poder público donde los MDD encontrarían, supuestamente, un espacio de realización, al poderse verificar una amplia tipología y mayor incidencia ciudadana debido a los efectos vinculantes que tenían, pues para el nivel nacional se previeron una iniciativa popular 
legislativa, de tipo formulada y no vinculante, y otra de reforma constitucional que sí obligaba a los poderes constituidos, así como un referendo facultativo a instancia del Congreso y otro obligatorio para la enmienda y reforma parcial de la Constitución.

Algunos de esos MDD en principio permitían que los ciudadanos actuaran como un contrapoder de los intereses de los grupos políticos en las estructuras decisoras del Estado. Lamentablemente, ninguno fue puesto en práctica mientras fue vigente la Constitución de 1940 (1940-1952 y 1954-19559-1958).

La Constitución de 1940 derivó en dos textos bastante diferentes, producto de dos coyunturas diversas pero con similar repercusión en el reconocimiento y funcionalidad de los MDD. Una fue la Ley Constitucional para la República de Cuba, decretada por Fulgencio Batista, cuando dio el golpe de Estado el 10 de marzo de 1952. Esta ley pretendió adaptar la Constitución de 1940 a las en ese momento nuevas circunstancias políticas, y concentró todo el poder en un Consejo de Ministros sobre el que Batista tenía total ascendencia. En cuanto a los MDD, la Ley Constitucional de 1952, aunque mantuvo la mayoría que regulaba ya la Constitución de 1940, limitó o suprimió a aquellos que, con un radio de acción nacional, podían atentar contra el statu quo. Por esto se suprimió la iniciativa legislativa para el nivel nacional, y se eliminaron las posibilidades de uso de los MDD que previó la Constitución de 1940 en el procedimiento de reforma.

La otra derivación fue la Ley Fundamental de 1959 (LF1959), la cual rigió después del triunfo de la Revolución durante el Período de Provisionalidad (1959-1976). Dicho texto retomó la mayor parte de la Constitución de 1940, aunque la parte orgánica, relacionada con la estructuración del poder y la cláusula de reforma, sufrieron notables modificaciones. Igual que en la Ley de 1952, un Consejo de Ministros concentraba las facultades legislativas y la mayor parte de las ejecutivas, además de las constituyentes; mientras que por otro lado se limitó la regulación constitucional de los MDD, en especial de los que podían utilizarse para subvertir el statu quo.

Se mantuvo la iniciativa legislativa de diez mil electores junto a la del $10 \%$ de los vecinos de un municipio para interesar su segregación, la cual conllevaba la celebración de un referendo al que se llegaba, preceptivamente, por acciones crediticias que generasen nuevos impuestos en el municipio y en la provincia. En sentido contrario, se proscribieron la iniciativa y el referendo, ambos con incidencia constitucional en cualquiera de sus variantes y que tributaban a la protección y defensa de la Constitución de 1940.

9 Entre 1952 y 1954 quedaron suspendidas las garantías constitucionales. Así, la Constitución de 1940 se restableció progresivamente después de 1954 a raíz de la victoria de Batista en las elecciones de ese año; para 1955 reformalizó su vigencia con su toma de posesión como presidente.

(T.) Y. Guzman Hernández | Los mecanismos de democracia directa en Cuba: diseño normativo y práctica Perfiles Latinoamericanos, 25(50) | FLACSO México | pp. 103-127 | DoI: 10.18504/pl2550-006-2017 
Igual que en la etapa anterior (1940-1959), los MDD que reguló la LF1959 quedaron sin desarrollarse en normas infraconstitucionales, ni tuvieron aplicación. El gobierno revolucionario validó la legitimidad de algunas de sus decisiones por medio de espontáneas manifestaciones del pueblo, entre las que merece un aparte la Primera y Segunda Declaración de La Habana que se consideraron como un ejercicio de la idea pura de la democracia (sobre la Primera, ÁlvarezTabío, 1988: p. 39) e incluso se les llegó a imputar naturaleza plebliscitaria, cuando en realidad fueron expresiones de un l'appel au peuple, ${ }^{10}$ ya en desuso. ${ }^{11}$

\section{La legitimación popular de la Constitución de 1976: ¿referendo o plebiscito?}

El tránsito de la LF1959 a la Constitución de 1976 trajo consigo la única consulta popular en las urnas de la historia constitucional de Cuba; la decisión fue adoptada por el Consejo de Ministros y el Buró Político del Partido Comunista. Esa consulta fue calificada como referendo (Vega, 1988: p. 119; Azcuy, 2004: p. 83, Guanche, 2011: p. 42), y además de que se oficializó con esa denominación (Ley No 1229/1975), justo recayó sobre la Constitución vigente para su aprobación. Previamente se había sometido a debate popular el anteproyecto, por lo que el pueblo podía modificar su contenido; pero la mayoría de esos cambios fueron poco sustanciales, basta comparar el anteproyecto con la Constitución aprobada.

El "referendo constitucional", en el que se incluyó la Ley de Tránsito Constitucional, terminó con 5473534 (97.69\%) de votos a favor, y 54070 (0.97\%) en contra; participaron 5602973 cubanos. El denominado "referendo" carecía

10 "Un llamado al pueblo". Es una institución de origen romano, en la cual, a través de la provocatio ad populum se apelaba al pueblo para recurrir la decisión de un magistrado o para revocarlos. En los límites de la participación directa, el l'appel au peuple se asocia a los plebiscitos napoleónicos y hitlerianos y se distingue de las consultas populares institucionalizadas (previamente reguladas) como el referendo y el plebiscito, porque en ella se someten a consideración popular temas políticos "paraconstitucionales" que se pretenden legitimar mediante una consulta extraordinaria (no reconocida en el ordenamiento jurídico como tal o para ese fin), y por un cuerpo electoral no coincidente numéricamente con el real. La Primera y Segunda Declaración de La Habana resultaron de dos alocuciones públicas de Fidel Castro, en ese entonces primer ministro. En la Segunda se reunieron más de un millón de cubanos en la Plaza Cívica, ahora Plaza de la Revolución, que aclamaron “¡Sí!”, y votaron a mano alzada los principios de política internacional de Castro. Ambas Declaraciones alcanzaron rango constitucional, algunos de los principios de política internacional de la Segunda, tales como antiimperialismo, anticolonialismo, autodeterminación de los pueblos e internacionalismo proletario, entre otros, se recogieron en la Constitución de 1976, que incluso llegó a declarar la base de las relaciones de Cuba con la Unión Soviética y el resto de los países socialistas. 
de apoyo legal en la reforma de la LF1959 y de cualquier otra norma vigente del ordenamiento jurídico cubano, salvo en la Ley № 1299, creada para la ocasión.

Algunos consideran a esta consulta popular de aprobación de la Constitución cubana en 1975 como un plebiscito vinculante (Altman, 2005: p. 218; Hevia, 2010: p. 177), otros han minimizado la trascendencia del proceso de elaboración de la Constitución de 1976, que involucró una participación directa sui generis (el debate popular) con un MDD, arguyendo que este (el proceso en su totalidad) ocurrió en un ambiente autoritario (Vergottini, 2009: p. 146), o con falta de libertades públicas (Asensi, 1996: p. 63). Así dicho se obvia que la Constitución de 1976 significó el cierre del Período de Provisionalidad, interregno útil a la progresiva institucionalización del naciente Estado revolucionario, y que por lo tanto, algunas de las prescripciones constitucionales ya tenían precedente en leyes y prácticas políticas anteriores.

El hecho de que las libertades individuales no fueron concebidas en la manera clásica legada por el liberalismo político para que fuesen oponibles al Estado, pudiera haber tenido ecos en el resto de los derechos políticos, y en particular en los MDD; por ello algunos de estos se regularon para solo promoverse desde el poder (referendo), otros en concierto con las estructuras estatales (iniciativa legislativa popular y ciertas revocatorias de mandato), o con incidencia limitada (la revocatoria de mandato).

\section{Los MDD en la Constitución de 1976. Generalidades}

Consecuente con el reconocimiento de la soberanía popular, la Constitución de 1976 previó el referendo "desde arriba" (a instancia de la Asamblea Nacional), la iniciativa legislativa popular, el referendo obligatorio para la reforma total de la Constitución o su modificación en contenidos específicos, y la revocación de mandato.

La reglamentación de la iniciativa legislativa, el referendo y la revocatoria de mandato quedó dispersa en leyes que no tributaron a su reforzamiento, sino que en algunos casos, vuelve inefectivos a estos mecanismos, por su incapacidad de subvertir la dinámica decisoria y de gestión en el marco de la representación; en otros, los convierte en instituciones débilmente vinculantes por quedar sujetas a los intereses generados en los órganos de poder estatal.

En la iniciativa legislativa se exigen requisitos que la desnaturalizan como herramienta ciudadana, en la medida que carece de autonomía y se dificulta mucho el proceder de los ciudadanos, además de que no vincula al órgano legislativo. El referendo solo puede ser iniciado "desde arriba" por la Asamblea Nacional, y se faculta al Consejo de Estado para complementar las normas de 
su procedimiento. En cuanto a la revocatoria popular de mandato, con la intervención popular se limitó a los delegados a las asambleas municipales del Poder Popular, y el procedimiento para su puesta en práctica es riguroso (Guanche, 2011: p. 76) por la mediación de comisiones y la supeditación del procedimiento a formalidades, entre otras cuestiones que obstaculizan su materialización.

La Constitución de 1976 institucionalizó la praxis política de la "consulta popular", ${ }^{12}$ por la que, en virtud del artículo 75, la Asamblea Nacional puede solicitar una consulta ciudadana y someter a debate o discusión popular un proyecto de ley en el marco del proceso legislativo. Este singular mecanismo participativo no debe entenderse como un MDD. Para este tipo de consulta no media el voto y la interpretación de los consensos y disensos que genera el debate queda a cargo de la Asamblea. ${ }^{13}$ Más bien se la ha calificado como un tipo de participación consultiva indirecta (Guanche, 2011: p. 83), o un mecanismo de participación directa (Noguera, 2006: p. 495). Por otro lado, se ha defendido la tesis de que el plebiscito se utilice bajo la cobertura del reconocimiento constitucional del referendo (Guanche, 2011: p. 42), lo que es forzado puesto que es posible conjugar el artículo 3 (soberanía popular) y el inciso u del artículo 75 (facultad de la Asamblea para celebrar consultas populares) desde una interpretación de la Constitución, aun cuando se adujera que dicha facultad es para la consulta en el marco del proceso legislativo en relación con la discusión popular (Álvarez-Tabío, 1988: p. 270), tal como se acabó de ver.

\section{El referendo. La omisión del referendo obligatorio en la reforma constitucional (1992)}

La reforma de 1992 ha sido la más profunda de la Constitución de 1976; pero no se ha llegado a un criterio uniforme sobre su envergadura, si se trató de una reforma parcial (Prieto, 2004: p. 45) o de un nuevo texto (Azcuy, 1992: pp. 41-52). Por otra parte, se ha discutido si entonces se debió emplear el referendo, ${ }^{14}$ debido a que con esa reforma se reconoció el derecho a elegir

12 Antes se habían consultado los códigos de la Niñez y la Juventud (1978), el Penal (1979), el de Trabajo (1984), y las leyes de Cooperativas de Producción Agropecuarias (1982) y General de la Vivienda (1984) (Nogueras, 2006: p. 495).

13 Así lo establece la insuficiente reglamentación de esta vía participativa en el último párrafo del artículo 72, cuando se prevé que: "Al término de la discusión, la comisión comunica los resultados a la Asamblea Nacional por medio del Presidente de esta y hace las recomendaciones pertinentes sobre las sugerencias y proposiciones de modificaciones que se hayan formulado." (Reglamento de la Asamblea Nacional del Poder Popular, G. O. no 2, 27 de diciembre de 1996).

14 La Constitución de 1976 previó el referendo en caso de que la reforma fuera total o se refiriera a la integración y facultades de la Asamblea Nacional o de su Consejo de Estado, o a derechos y deberes con- 
directamente a diputados y delegados a las Asambleas Nacional y Provincial, respectivamente, lo mismo que la libertad religiosa y de cultos.

Se ha sostenido que la obligatoriedad del referendo dependía de que con la reforma a la Constitución se limitara, restringiera o eliminara el ejercicio de los derechos (o se ampliasen los deberes), y similar solución se sugirió para cuando se disminuyesen las facultades de los órganos estatales y la calidad de estos, refiriéndose a la legitimidad directa o indirecta de sus miembros (Pérez, 1992: p. 6). ${ }^{15}$ Lo cierto es que el referendo debió usarse en 1992, pues al margen de los derechos y libertades adicionados, se perdió la certeza jurídica de todos, al agregarse el estado de emergencia a la Constitución. ${ }^{16}$ Por tal causa se prescribió constitucionalmente que una ley determinaría los derechos y deberes fundamentales reconocidos por la carta magna, cuyo ejercicio sería regulado de forma diferente mientras dure un estado de emergencia. ${ }^{17}$ Por ende, de alguna manera se limitaron y restringieron los derechos constitucionales, pues la limitación o restricción de estos son consecuencias "naturales" de las situaciones de excepción.

Además, la tesis de Pérez Milián se acoge a una interpretación extensiva de la Constitución, solo que técnicamente obvió que este tipo de interpretaciones es válida mientras no signifique limitaciones de derechos, y en este caso se estaba cercenando el derecho de participación, a la vez que se impidió que el pueblo expresara en referendo su opinión (vinculante) sobre la reforma de su Constitución.

\section{La iniciativa legislativa popular: una iniciativa de agenda controlada}

La iniciativa legislativa popular fue una novedad de la Constitución de 1976, respecto a sus predecesoras (Vega, 1988: p. 253), pero fue concebida para no contradecir los intereses del Estado. Tal afirmación se deduce de los requisitos que ha exigido la norma de desarrollo — en este caso, el Reglamento de la

sagrados en la Constitución. (Art. 141, Constitución de la República, G. O. no 18, 24 de febrero de 1976).

La interpretación ajustada del segundo párrafo del artículo 141 tenía que ver sobre todo con que en la reforma de 1992 se reconoció el derecho a elegir directamente a los diputados a la Asamblea Nacional (art. 71) y a los delegados a la Provincial (art. 135, II\$), también se reconoció por primera vez la libertad religiosa y de cultos (art. 55).

16 Art. 9, Ley de Reforma Constitucional, G. O. no 1157, 13 de agosto de 1992.

17 Art. 67, Constitución de la República. G. O. no 3, 31 de enero de 2003; la ley aludida es la No. 75 "De la Defensa Nacional", que en su artículo 10 si bien relaciona los derechos, libertades y garantías que serán regulados de manera diferente, ante la ocurrencia de una de las situaciones excepcionales previstas en la ley, no establece cómo serán afectados. Estos son los derechos al trabajo, manifestación, reunión y asociación, las libertades de palabra y prensa, así como la inviolabilidad del domicilio y la correspondencia, y el régimen de tutela al detenido. G. O. no 1, 13 de enero de 1995.

(T.) Y. Guzman Hernández | Los mecanismos de democracia directa en Cuba: diseño normativo y práctica Perfiles Latinoamericanos, 25(50) | FLACSO México | pp. 103-127 | DoI: 10.18504/pl2550-006-2017 
Asamblea Nacional del Poder Popular- para su puesta en práctica, por lo que parecería condenada al fracaso si se la entendiera como opuesta a la agenda política del Estado, con lo que se ha restado virtualidad jurídica y política a la institución, además de que en la fase de recolecta de firmas se atenta contra el principio de participación.

La iniciativa legislativa popular en Cuba es de tipo formulada, y se exige a los solicitantes que acompañen el proyecto de ley con una extensa y exhaustiva fundamentación desagregada en varios aspectos de facticidad económica, social y legal. Otro requisito obliga a los promoventes a coordinarse con los órganos y organismos que deben cumplir o hacer cumplir las regulaciones propuestas y mostrar en el escrito de solicitud sus resultados, antes de presentar la iniciativa. No se conoce qué ocurriría si los órganos u organismos se opusieran al contenido de esta última, o sea, si tal acción de coordinación es de medio o de resultado. Si fuese lo primero, no sería relevante, de lo contrario, quedaría enclaustrado en los designios o intereses de las estructuras estatales. Por último, llama también la atención que se exija a los solicitantes que acrediten sus firmas y su capacidad para ejercer el sufragio activo y pasivo en documento notarial.

Respecto a esto último, lo político-racional sería que el Estado habilitase puntos de recolecta de firmas de fácil acceso para los ciudadanos, en los que agentes electorales para la ocasión garantizaran la fidelidad e idoneidad de las firmas sin costo alguno, en un horario flexible y con la debida publicidad. Algunas prácticas foráneas muestran la colaboración del Estado en las iniciativas legislativas, e incluso llega al apoyo económico (Hevia, 2010: p. 163). Por último, la cantidad de firmas exigidas para la iniciativa (diez mil), que ha representado entre el 0.0016 y el $0.0011 \%$, teniendo en cuenta los picos del registro de votantes y electoral en Cuba desde 1980 hasta 2012, se encuentra entre los porcentajes más bajos en América Latina y Europa.

Se ha llegado a sostener que la iniciativa legislativa promovida por las Organizaciones Sociales y de Masas (OSM) ${ }^{18}$ configura un mecanismo directo de poder desde la ciudadanía (Guanche, 2011: p. 43). Esta opción no asegura por sí sola el carácter directo de la iniciativa legislativa, ya que según establecen la Constitución (art. 88) y el Reglamento de la Asamblea Nacional (art. 62), las direcciones nacionales de las osm y el Comité Nacional de la Central de Trabajadores de Cuba (стс) estarían actuando en representación de los sectores de la sociedad civil cubana que particularmente agrupan, cuyas demandas deben

18 Las Organizaciones Sociales y de Masas son asociaciones no gremiales, por su dinámica de agrupación de grandes sectores sociales, no quedan debidamente compartimentadas, y en general la población pertenece a más de una. Aun cuando la reforma constitucional de 1992 suprimió que asumían funciones estatales, no dejan de tener naturaleza público-política. 
agregar y proyectar políticamente; en consecuencia, sus respectivas directivas representadas en un sujeto podrían promover la iniciativa legislativa en concepto de sujeto político facultado, sin tener que acompañar su solicitud con firmas de los ciudadanos. Así lo han hecho la Federación de Mujeres Cubanas (FMC) con el Código de Familia, y la Asociación Nacional de Agricultores Pequeños con la Ley de Cooperativas de Producción Agropecuarias (Guanche, 2010: p. 61; Nogueras, 2006: p. 495).

$\mathrm{Al}$ margen del vínculo que exista entre la dirección de la osm y el sector popular que agrupa, la primera actúa representando a la segunda. Para que se configure una iniciativa legislativa de naturaleza popular será necesario validar la promoción con suficientes firmas u otros actos contrastables que demuestren el apoyo popular a la iniciativa. A eso súmese que en disímiles legislaturas la máxima directiva de algunas osm ha formado parte de la Asamblea Nacional o del Consejo de Estado, y en Cuba los diputados pueden tener iniciativa legislativa (art. 16, inc. d, Reglamento de la Asamblea Nacional), por lo que, siendo esta un típico mecanismo iniciado "desde abajo", en esta variante no cabría la certeza acerca de cuándo un diputado que fuera presidente de una osm actuaría en función de las demandas de los sectores sociales que la organización que dirige logra definir, y cuándo en función de los intereses de los representados, pero generados desde el poder estatal, ${ }^{19}$ a no ser que pueda constatarse un movimiento popular de abajo, o sea, desde las estructuras inferiores o de base de las osm.

Por otro lado, nada impide que en Cuba diez mil cubanos firmen una iniciativa legislativa, tal como lo establece la Constitución y el Reglamento de la Asamblea Nacional. Sin embargo, el fuerte control social que han ejercido algunas elementos institucionales del sistema, junto a una reacción de retraimiento ante determinadas prácticas políticas institucionalizadas, que en determinados contextos han sido traducidas como ataques al proceso revolucionario, ${ }^{20}$ tal vez influyan en que la iniciativa popular quede reconducida hacia las formas de

19 Esta bifurcación de intereses puede darse porque no obstante que la Asamblea Nacional representa y expresa la voluntad soberana de todo el pueblo (art. 69 constitucional), los miembros del Consejo de Estado son electos por ella entre sus diputados, por lo tanto, no lo son popularmente; la legislación que este órgano produce anualmente es muy superior en número a la que produce la Asamblea; ni los diputados de la Asamblea ni los miembros del Consejo son revocables popularmente, y la rendición de cuentas de uno y otro órgano funciona como control interorgánico, aun cuando la rendición de la Asamblea la remita a la base, una vez que los diputados deben hacerlo ante la Asamblea Municipal del Poder Popular del territorio por el que resultaron electos.

20 "Otras limitaciones psicológicas, por el contrario, son el resultado [...] del conocimiento implícito o atribuido acerca de cuáles son los marcos restrictores establecidos - en lo normativo y en la interpretación ideológica-, que pueden conllevar una carga de autoatribución de culpa (castigo potencial percibido, autoamenaza de exclusión, temor de dańo indirecto a las metas individuales y de la colectividad, etc.), y de punición velada o represalias sutiles como mecanismo grupal o social de castigo real por la disensión expresada sobre determinadas normas o construcciones ideológicas sobre las que está prohibido debatir 
articulación ciudadana institucionalizada del inciso d del artículo 88 constitucional. Esto no quiere decir que se deba materializar a través de las osm reconocidas legalmente, porque en Cuba existen grupos de profesionales (periodistas, juristas, economistas, entre otros), religiosos, académicos y de otra naturaleza, que integran la sociedad civil cubana con suficiente fuerza y membresía para lograr tal propósito.

\section{El Proyecto Varela (2002). El intento de hacer trascender la iniciativa de agenda en objetivo y carácter}

La reforma a la Constitución de 2002 se fundamentó oficialmente en la postura agresiva del gobierno norteamericano. Las dos alocuciones (una en Miami) de George W. Bush, entonces presidente de Estados Unidos, que pronunciara el 20 de mayo en conmemoración del centenario de la República cubana, acarrearon una respuesta inmediata del gobierno cubano. En el escenario interno, en abril de ese año, Oswaldo Payá, exlíder de un grupo de la disidencia en Cuba, con apoyo logístico de la Oficina de Intereses de los Estados Unidos en Cuba y de algunos gobiernos de la Unión Europea, presentó a la Asamblea Nacional una iniciativa legislativa popular bautizada como Proyecto Varela, que por su contenido trascendía a la Constitución.

Las propuestas del Proyecto Varela consistían en derechos a la libre expresión y asociación; amnistía a los encarcelados por motivos políticos y libertad de los detenidos por practicar derechos humanos que las leyes actuales no reconocen; derecho de los cubanos a formar empresas tanto de propiedad individual como cooperativa; y una nueva ley electoral que modificara la nominación de los candidatos y el propio sistema de elección de los mismos (véase los contenidos en De la Cuesta, 2007: pp. 519-531). En ese escrito se solicitaba a la Asamblea que sometiera a consulta popular, mediante referendo, cada una de esas propuestas. Esto último si bien desbordaba los límites legales de la iniciativa legislativa en Cuba, al no contar con apoyo en las normas que la reglamentaban, trataba de estimular a la Asamblea para que usara su facultad de convocar a referendo, según lo preceptuado constitucionalmente; se pretendía vincular un MDD "desde abajo" con otro "desde arriba" para buscar la vinculación legal del resultado.

Para el Proyecto Varela se reunieron más de las diez mil firmas requeridas, que no fueron validadas por el órgano legislativo, aunque tampoco el proyecto cumplía con algunos de los requisitos que establecía el Reglamento de la Asam-

y, por tanto, se constituyen en la instancia psicológica individual y colectiva, como un mecanismo de autoveto, autocensura o autorrepresión." (D’Angelo, 2004: p. 95). 
blea Nacional. No se dio respuesta oficial, al menos de carácter público. Dos de las cuestiones de forma que pudieron motivar la desestimación de la solicitud tal vez fueron lo relativo a la necesidad de que los promoventes acompañaran las solicitudes con declaración jurada ante notario público, ${ }^{21}$ y que se consignase en la fundamentación el resultado de las coordinaciones hechas con los órganos y organismos estatales que estaban involucrados con la materialización de las propuestas. ${ }^{22}$

\section{La legitimación de la reforma constitucional de 2002 ¿Iniciativa popular de reforma constitucional en Cuba?}

La reforma de la Constitución de 2002 acaeció inmediatamente después del fracaso del Proyecto Varela, tomando como base una propuesta de la Asamblea Conjunta de las direcciones nacionales de las osm dirigida a la Asamblea Nacional. La propuesta tenía como objetivo principal la reafirmación del socialismo, con claras (aunque indirectas) miras a dos aspectos que funcionan como anclajes político-ideológicos del sistema político cubano: la dirigencia y superioridad del PCC como única fuerza política del sistema, y la preeminencia y control del Estado sobre la propiedad y la economía.

La iniciativa de reforma constitucional, según el procedimiento de reforma previsto (art. 137), parecía tenerla únicamente la Asamblea Nacional, pero la propia Constitución reformada formalizó un sujeto distinto, ${ }^{23}$ a la vez que reconoció la iniciativa de las osm. Esto último trasciende para considerar o

21 El artículo 64 del Reglamento de la Asamblea Nacional del Poder Popular establece: "Si la iniciativa procede de los ciudadanos, conforme se establece en el inciso g) del artículo 88 de la Constitución, además de la fundamentación consignada en los acápites precedentes, los ciudadanos promoventes del proyecto, acompañan declaración jurada ante notario, donde se acreditará la identidad personal mediante los datos del carné de identidad como documento idóneo y probatorio de la individualización de una persona, así como de que no está invalidada para ejercer el sufragio activo o pasivo." (Reglamento de la Asamblea Nacional del Poder Popular, G. O. no 48, 27 de diciembre de 1976).

22 Este último requerimiento atenta contra la autonomía de esta institución participativa, ya que haría depender su curso del criterio de los órganos y organismos estatales vinculados a la puesta en práctica de la "pretensión normativa”. El reglamento no especifica si esas coordinaciones son de medio o de resultado, o sea, si bastaría hacer las coordinaciones o si los promoventes deberían presentar un aval del órgano u organismo en cuestión que muestre los resultados de dichas coordinaciones. ¿Qué ocurriría si existieran intereses contrapuestos entre los promoventes y los órganos u organismos estatales, y estos últimos se opusieran a la nueva regulación? Ante esta situación, ¿qué resultados podrían presentar los primeros como fundamentación de su iniciativa? Véase el artículo 63 del Reglamento de la Asamblea Nacional del Poder Popular, G. O. no 48, de 27 de diciembre de 1976.

23 La Disposición Especial estableció que casi la totalidad del pueblo cubano expresó su más decidido apoyo al proyecto de reforma constitucional propuesto por las organizaciones de masas. (Constitución de la República de Cuba, G. O. no 3, de 31 de enero de 2003). 
reconsiderar si en Cuba diez mil ciudadanos tendrían iniciativa para reformar la Constitución, como un MDD iniciado "desde abajo", sin efecto vinculante. En Cuba, la iniciativa legislativa la tienen diez mil ciudadanos, como se explicó, pero también las direcciones nacionales de las osm y la Central de Trabajadores de Cuba (стс), por lo tanto, al legitimarse la segunda en función de la reforma de la Constitución debió quedar legitimada también la primera, desde una lógica constitucional. No obstante, desde finales de los setenta se había reconocido la existencia de una iniciativa popular de reforma constitucional (Álvarez-Tabío, 1988: p. 426). Esta importante cuestión todavía sigue sin zanjarse, y requerirá en su momento una interpretación oficial del precepto constitucional, o seguirá respondiendo a soluciones de coyuntura política.

\section{La legitimación de la nueva reforma constitucional. La recolecta de firmas de adhesión convertida nominalmente en plebiscito. (Volviendo a la iniciativa legislativa popular a través de las osm)}

Como mecanismo legitimador de la reforma de 2002 que significó introducir en la Constitución una cláusula de intangibilidad y con ello límites a su reforma, la dirección política, en ese momento liderada por Fidel Castro, decidió que los cubanos mostraran su apoyo a la iniciativa de reforma consignando su firma. Para ello se habilitaron las locaciones que habitualmente se utilizan como centros de votación. La Asamblea Nacional tenía la facultad constitucional de convocar a referendo, pero se optó por una vía sui generis en Cuba. La sustitución del voto por firmas, técnicamente, no garantizó que, utilizando una tesis de Altman, los ciudadanos en condiciones de igualdad expresaran lo más fielmente posible su potencia soberana, cuestión que, propuesto en estos extremos, solo es posible a través del voto libre y secreto (Altman, 2010: p. 11).

Teniendo en cuenta la connotación del límite a la reforma que se introducía, se requería un modo de legitimación popular, para lo cual el referendo tiene una idónea funcionalidad. Sin embargo, se desechó su uso, lo que hubiese permitido obtener con mayor claridad el nivel de consenso que tenía tal decisión política, pues se optó por mostrar la legitimidad del cambio constitucional, que significaba la irreversibilidad del socialismo y del sistema político-social, a través de marchas populares y una recolecta de firmas de adhesión.

Para algunos se trató de un plebiscito (Toledo, 2002: p. 6), otros lo han denominado referendo informal (Valdés, 2009: p. 157). Por otra parte, en el discurso oficial, la recolecta de firmas fue entendida como apoyo a la iniciativa de las direcciones nacionales de las osm (Alarcón, 2002: p. 4; Toledo, 2002: p. 6), lo que ha tributado a la confusión respecto a cómo se configura la iniciativa 
legislativa popular en Cuba, al pretenderse conectar las firmas recogidas con la iniciativa de las osm, como fases de un mismo mecanismo.

La recolecta de firmas si bien se usó para mostrar la legitimidad de la reforma constitucional de 2002, no puede considerarse plebiscito ni referendo, ya que para ambos, el voto con todas sus garantías, y al menos una mínima reglamentación previa que se pronuncie sobre el efecto jurídico del resultado y las garantías de la institución en sentido general, son elementos esenciales para su configuración jurídica. La promoción legislativa que hagan las direcciones nacionales de las OSM, acompañada de firmas ciudadanas que se recolecten posteriormente, configuraría una segunda variante de la iniciativa legislativa popular en Cuba, tal vez en este caso, por el posicionamiento de las osm en el sistema político cubano, debiera ser vinculante, obligando a la Asamblea a aprobar el proyecto de ley.

La revocatoria de mandato. Que no significa necesariamente revocatoria popular de mandato

En Cuba el término revocatoria de mandato ha englobado tanto a la revocatoria popular de mandato propiamente dicha, es decir, a aquella que ha involucrado a los electores en la solicitud o en la consulta decisoria (mixed recall) o en ambas (full recall), como a la revocatoria (remoción propiamente dicho) que se asemeja más al impeachment que a cualquier otra institución del control horizontal o vertical. ${ }^{24}$

La "revocatoria" de los delegados provinciales y diputados de la Asamblea Nacional únicamente ha podido ser sustanciada (solicitada y decidida) por el $25 \%$ de los delegados municipales de la Asamblea, correspondiente a la circunscripción electoral por la cual resultó electo el revocable, o por un miembro del órgano al que pertenece. En el caso de los miembros del Consejo de Estado - órgano que en Cuba tiene una marcada carga decisoria, a partir de que sus decretos-ley han sido equiparados a la ley con efectos secundum legem (en el sentido de la ley) y contra legen (contrario a la ley) (Marill, 1989: p. 228)—, han podido ser revocados por la Asamblea Nacional que los elige de su seno, o por otro miembro del mismo órgano. Lo curioso es que en todos los casos, una Comisión de Ética analiza la solicitud y puede considerar que no hay motivos

24 La revocatoria de mandato descrita en esos extremos, actualmente la regula la Ley No. 89 "De la revocación de mandato de los elegidos a los órganos del Poder Popular”, G. O. No. 62, de 23 septiembre 1999. Siete ańos después de la reforma constitucional de 1992 se reguló en una ley independiente, aunque antes se había hecho en las leyes electorales 1305 y 37 de 1976 y 1982, respectivamente.

(T.) Y. Guzman Hernández | Los mecanismos de democracia directa en Cuba: diseño normativo y práctica Perfiles Latinoamericanos, 25(50) | FLACSO México | pp. 103-127 | DoI: 10.18504/pl2550-006-2017 
para iniciar la mal denominada revocación; incluso cuando se ha tratado de delegados municipales con doble representación, ${ }^{25}$ se escucha el parecer de la Comisión, cuyo efecto será paralizador si así lo considera.

La revocabilidad de todos los representantes del poder popular ha sido pensada como una necesidad en pos de la democratización del sistema político cubano (Guanche, 2011: p. 109; Sansónov, 2012: p. 68; Guzman, 2014: p. 203). Extender el radio de acción de este mecanismo a las Asambleas Provincial y Nacional, así como al Consejo de Estado, conduciría a un rediseño de la Constitución y la ley electoral; de esta última en lo relacionado con la representatividad territorial de los delegados provinciales y diputados nacionales.

Gráfico 1. Descenso sufrido en la práctica de la revocatoria popular de mandato en Cuba (1976-2015)

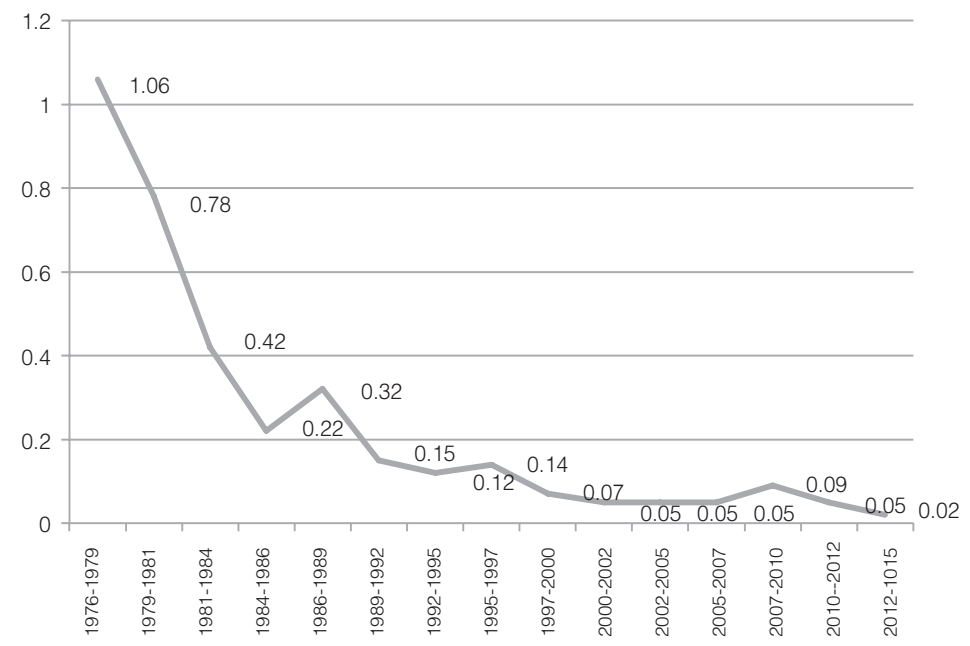

Fuente: Elaboración propia con datos de la Asamblea Nacional del Poder Popular.

No obstante, la revocación de mandato puede permanecer limitada a los delegados de la Asamblea Municipal. Para contrarrestar su progresivo desuso 26 (gráfico 1) se deberían redefinir determinados presupuestos relacionados con el

25 En Cuba un delegado a la Asamblea Municipal del Poder Popular puede ser electo además para una Asamblea Provincial y/o para la Nacional.

26 Los porcentajes extremos de delegados municipales que han cesado su mandato se encuentran entre el 12.36 y el $8.43 \%$ en el VII mandato (1993-1995) y IV mandato (1984-1986), para una media histórica de $10.10 \%$; mientras que de delegados municipales revocados se encuentran entre 1.06 y $0.03 \%$ en 
diseño del municipio y del poder local, en pos de su descentralización y autonomía, lo que acarrearía más facultades para los representantes a esa instancia y, por lo tanto, mayor responsabilidad política por el ejercicio de su cargo. En otro sentido, se hace necesario que los delegados a elegir presenten un documento base que sirva de guía al elector para conocer sus compromisos con la localidad y el municipio, incluso sobre la base de los presupuestos anteriores; así sería valorable la facticidad de una revocatoria con efecto disolutorio de la Asamblea Municipal, al estilo suizo.

\section{Valoraciones generales y propuestas. A modo de conclusión}

La regulación y puesta en práctica de los MDD en Cuba ha sido errática. La Constitución de 1940 ha sido la más profusa en el reconocimiento de estos mecanismos, si bien en poco más de quince años de vigencia ninguno pudo materializarse. Esa legislación anticipó en su regulación cuestiones de diseño que deben retomarse en la actualidad, sobre todo en lo concerniente a la iniciativa de reforma constitucional, y a la dinámica de la democracia directa para el nivel municipal, que requeriría en estos momento de un sustancial cambio en la concepción del municipio en Cuba, en pos de su descentralización y autonomía.

Desde una concepción restringida de los MDD, el ordenamiento jurídico cubano solo reconoce al referendo facultativo y preceptivo - este último restringido a tópicos específicos de la reforma de la Constitución-, y a la revocatoria de mandato, circunscrita al nivel municipal. Desde una concepción amplia se adicionaría la iniciativa de agenda. En sentido general, la perspectiva funcional de los MDD ha respondido a una peculiar concepción de los derechos políticos y a un marcado carácter centralista del ejercicio del poder, lo que los convierte en instrumentos ciudadanos que no se oponen al Estado.

El diseño institucional de los MDD en Cuba presenta diversas limitaciones: concentración en el nivel nacional, y escasa previsión de referendos preceptivos, así como de mecanismos que se activen "desde abajo", lo que repercute negativamente en el empoderamiento ciudadano. Algunas prescripciones van en contra de las tendencias regulatorias más aceptadas, entre las que destacan la facultad de promover la revocatoria de mandato solo a los que eligieron al revocable; la indeterminación temporal para hacerla efectiva; las acciones retardatarias para la promoción de la iniciativa legislativa, tales como firmas ante notario público, y necesidad de una exhaustiva fundamentación que acompañe el proyecto de ley.

el I mandato (1976-1979) y XV (último) mandato (2012-2015), para una media histórica de 0.25\%.

(Datos ofrecidos por la Asamblea Nacional del Poder Popular).

(T.) Y. Guzman Hernández | Los mecanismos de democracia directa en Cuba: diseño normativo y práctica Perfiles Latinoamericanos, 25(50) | FLACSO México | pp. 103-127 | DoI: 10.18504/pl2550-006-2017 
La descentralización y autonomía municipal son trascendentes para la reanimación de los MDD, y para llenar de nuevo contenido a la participación en los marcos de la democracia socialista en Cuba. En la actualidad, a causa de la inercia política del municipio y de las limitaciones en la gestión, decisión y representación de las autoridades locales, algunos de estos mecanismos se han quedado progresivamente vacíos o experimentan una regresión, otros quedan sin razón de lege ferenda (a regularse en ley), como son los casos de las iniciativas legislativas y el referendo.

De forma particular pudiera sugerirse la regulación de la iniciativa popular de referendo. También la superación de la actual iniciativa de agenda, por una legislativa, en los términos que hoy se entiende, en la que además se suprima el concierto con los organismos e instituciones del Estado, en la que sea suficiente una exposición de motivos, y en la que se sustituyan las firmas ante notario público por puntos de recolecta, con fedatarios públicos ad hoc. En los límites de la iniciativa legislativa es necesario que se prevea la posibilidad de que la Asamblea Nacional presente una contrapropuesta que pueda votarse popularmente de conjunto con la presentada por los promoventes, y que se imbrique la iniciativa ciudadana con la de las osm, siempre que se conciba progresivamente, de modo transparente y verificable desde las estructuras de base, pudiendo, en estos casos, exigirse solo la firma de tres mil a cinco mil ciudadanos para dotar de legitimidad la solicitud. Por último, que la Asamblea Nacional esclarezca por vía de interpretación constitucional si existe iniciativa ciudadana de reforma constitucional o se reconozca taxativamente en la cláusula de reforma, y que se reconozca constitucionalmente el referendo preceptivo como mecanismo de protección ante cualquier iniciativa de reforma a la carta magna.

En el caso de la revocatoria de mandato, que se atempere su regulación a determinados estándares: permanencia del bajo umbral de firmas para la solicitud (en Cuba aumentó del 20 al 25\%, con la última modificación de las normas de la revocatoria), activación después de la primera mitad del mandato del electo (por ahora no existe límite), participación no solo de los que eligieron al revocable, sino de todos los que caen bajo su órbita de representación (Guzman, 2014: pp. 199-200), establecimiento de términos para cada fase del proceso, de forma tal que en su totalidad sea lo más expedito posible (los términos pueden variar en dependencia de si la revocatoria al delegado municipal es iniciada por otro delegado o por el $25 \%$ de los electores, además puede depender de la cercanía de las sesiones de la Asamblea) (Guanche, 2011: p. 108; Guzman, 2014: pp. 200-201); y supresión en la ley de las mediaciones de las órganos superiores del poder estatal, en los supuestos de doble representación.

La concepción actual de los MDD que hoy se propugna desde la teoría, no solo tributa en mayor medida al ejercicio de la democracia directa, sino también 
al empoderamiento ciudadano, a la generación de una ciudadanía más activa, a la obtención de consensos cuantitativamente verificables, a la socialización de las políticas públicas, y a la simetría entre los ciudadanos y los que ejercen el poder, entre otros efectos positivos deseados.

\section{Referencias}

Altman, D. (2011). Direct Democracy Worldwide. Cambridge y Nueva York: Cambridge University Press.

Altman, D. (2010). Plebiscitos, referendos e iniciativas populares en América Latina: ¿̇mecanismos de control político o políticamente controlados? Perfiles Latinoamericanos, 18(35), 9-34.

Altman, D. (2005). Democracia directa en el continente americano: ‘autolegitimación gubernamental o censura ciudadana? Política y Gobierno, XII(2), 203-232.

Álvarez-Tabío, F. (1988). Comentarios a la Constitución socialista. La Habana: Ciencias Sociales.

Álvarez-Tabío, F. (1953). Evolución constitucional de Cuba (1928-1940). La Habana: Talleres Gráficos.

Azcuy, H. (2010). Análisis de la Constitución cubana y otros ensayos. La Habana: Instituto de Investigación Cultural Juan Marinello/Ruth Casa Editorial.

Azcuy, H. (1992). La reforma de la Constitución Socialista de 1976. Cuadernos de Nuestra América, $I I(22), 41-52$.

Bihari, O. (1979). The Constitutional Models of Socialist State Organization. Budapest: Akadémiai Kaisó.

Bobbio, N. et al. (1983). Dizionario di politica. Torino: Unione Tipograficco-Editirice Torinese.

De La Cuesta, L. A. (2007). Constituciones cubanas. Miami: Alexandria Library.

D’Angelo, O. (2004). Participación y construcción de la subjetividad social para una proyección emancipatoria. En Linares Fleites, C. et al. (Comp.). La participación. Diálogo y debate en el contexto cubano. La Habana: Centro de Investigación y Desarrollo de la Cultura Cubana Juan Marinello.

Garcini, H. (1976, Julio-Diciembre). La Constitución socialista de 1976. Revista Cubana de Derecho, (12), 103-119.

(T.) Y. Guzman Hernández | Los mecanismos de democracia directa en Cuba: diseño normativo y práctica Perfiles Latinoamericanos, 25(50) | FLACSO México | pp. 103-127 | DoI: 10.18504/pl2550-006-2017 
Guanche, J. C. (2011). Estado, participación y representación en Cuba. Diseño institucional y práctica política tras la reforma constitucional de 1992. Buenos Aires: CLACso. Recuperado el 20 de junio de 2013, de http://www.bibliotecavirtual.clacso.org.ar/clacso/becas/.../guanche201105.pdf

Guzman Hernández, T. Y. (2013). Cuba: deudas pasadas y retos presentes desde la norma. En Welp, Y. \& Uwe, S. (Coords.). La dosis hace el veneno. Análisis de la revocatoria de mandato en América Latina, Estados Unidos y Suiza (pp. 187-205). Quito: Instituto de la Democracia.

Hevia de la Jara, F. (2010, enero-abril). La iniciativa legislativa popular en América Latina. Convergencia, $17(52), 155-185$.

International IDEA. (2008). Direct Democracy. The International Handbook. Stokholm: International Institute for Democracy and Electoral Assistance.

Madrid, M. de la. (2000). Las formas de la democracia directa. En Concha Cantú, H. A. (Coord.). Sistema representativo y democracia semidirecta (Memoria del VII Congreso Iberoamericano de Derecho Constitucional) (pp. 435-436). México: unam.

Lissidini, A., Welp, Y. \& Zovatto, D. (Coords.). (2011). Democracia directa en América Latina. Buenos Aires: Prometeo.

Marill Rivero, E. (1989). Constitución de la República de Cuba. Temática/Legislación complementaria. La Habana: Ciencias Sociales.

Marill Rivero, E. (1980, Enero-Diciembre). Acerca de la dialéctica entre la democracia y la legalidad socialistas. Revista Cubana de Derecho, (16), 97-141.

Noguera Fernández, A. (2006, Julio-Septiembre). La participación popular en Cuba. Análisis jurídico y propuestas dentro del contexto cubano para su perfeccionamiento. Foro Internacional, XVLI(3), 493-512.

Pérez Milián, F. (1992, Julio-Septiembre). Motivos para una reforma. Revista Cubana de Derecho, (7), 3-8.

Prieto Sansonov, D. et al. (2012). Dossier sobre los desafíos constitucionales de la República de Cuba. En González Mederos. L. (Ed.). Por un consenso para la democracia (pp. 49-71). La Habana: Espacio Laical Publicaciones.

Prieto Valdés, M. (2004). La reforma a la constitución cubana de 1976. En Prieto Valdés, M. \& Pérez Hernández, L. (Comps.). Temas de derecho constitucional cubano (pp. 45-50). La Habana: Félix Varela. 
Svenson, P. (2011). Forms and Terminology of Direct Democracy. Recuperado el 20 de diciembre de 2014, de http://paperroom.ipsa.org/papers/paper_26306.pdf

Rial. J. (2000). Instituciones de democracia directa en América Latina. Recuperado el 22 de diciembre de 2014, de http://redpartidos.org/files/democraciadirecta.pdf

Valdés Paz, J. (2009). El espacio y el límite. Estudios sobre el sistema politico cubano. Panamá: Instituto Cubano de Investigación Cultural "Juan Marinello"/Ruth Casa Editorial.

Vega Vega, J. (1988). Derecho constitucional revolucionario en Cuba. La Habana: Ciencias Sociales.

Vergottini, G. (2009). Derecho constitucional comparado. México: IIJ-UnAM.

Welp, Y. (2010, Julio-Agosto). El referendo en América Latina. Diseños institucionales y equilibrios de poder. Nueva Sociedad, (228), 26-42.

Zovatto Garetto, D. (2007, Segundo Semestre). Las instituciones de democracia directa a nivel nacional en América Latina: Un balance comparado: 1978-2007. Revista de Derecho Electoral, (4), 1-52.

Recibido el 9 de mayo de 2015. Aceptado el 30 de junio de 2016. 